\title{
ANALISIS KESIAPAN SISWA DALAM MENGIKUTI EKSTRAKULIKULER KIR BERWAWASAN SAINS DAN TEKNOLOGI DI SMP
}

\author{
Ngurah Mahendra Dinatha \\ Pendidikan IPA STKIP Citra Bakti, NTT \\ ngurahm87@gmail.com
}

\begin{abstract}
Abstrak
Penelitian ini bertujuan untuk mengetahui kesiapan siswa dalam mengikuti ekstrakulikuler KIR berwawasan sains dan teknologi di SMP Widiatmika. Penelitian ini merupakan penelitian deskriptif kuantitatif. Sampel yang digunakan sebanyak 40 orang siswa. Pengumpulan data kesiapan siswa dalam mengikuti ekstrakulikuler KIR berwawasan sains dan teknologi menggunakan kuesioner. Data dianalisis secara deskriptif kuantitatif dengan mengacu skala teoretik. Dari hasil penelitian diperoleh data bahwa kesiapan siswa dalam mengikuti estrakulikuler KIR berwawasan sains dan teknologi di SMP Widiatmika dikatakan dalam kategori "Sangat Baik" dengan jumlah 16 siswa dan persentase sebesar 40\%, sedangkan sebanyak 24 siswa berada pada kriteria "Baik" dengan perentase 60\%. Sehingga secara umum kesiapan siswa dalam mengikuti estrakulikuler KIR berwawasan sains dan teknologi di SMP Widiatmika sudah dapat dikatakan "Baik".
\end{abstract}

Kata kunci: Kesiapan siswa, KIR berwawasan sains dan teknologi.

\begin{abstract}
This present study aims to investigate students eagerness to join Students Scientific Work club with science and technological basis. This study took place at SMP Widiatmika involving 40 students as the sample of the study. Further, this study employs a descriptive quantitative design and utilize questionnaire as means to collect the data. The data collected are further analysed descriptive quantitatively by referring to theoretical scale. The result of the study shows that there are 16 students or $40 \%$ of total sample who are categorized as very good in terms of their eagerness to join scientific work club. On the other hand, there are 24 students or $60 \%$ who are categorized as good. Thus, it can be concluded that students' readiness to join scientific work club with science and technological basis in SMP Widiatmika is good.
\end{abstract}

Keywords: investigate students, Students Scientific Work club with science and technological basis.

\section{Pendahuluan}

Kualitas hasil belajar siswa sekolah sangat terkait dengan proses pembelajaran yang dilaluinya. Beberapa penelitian dalam sains telah banyak dilakukan (Laksana, 2017). Pembelajaran mengarah pada pola active leaning, dimana siswa harus dapat mengerahkan segala kemampuannya untuk mengolah pikir dan rasionalnya dalam mempelajari topik yang menjadi target pembelajarannya. Namun pada saat ini hasil belajar siswa, khususnya siswa SMP masih rendah karena faktor kesulitan belajarnya (Dinatha, 2017). Untuk menanggulangi hal tersebut banyak cara yang bisa dilakukan yaitu dengan cara saling berinteraksi antar siswa. Siswa akan lebih baik bila berinteraksi satu sama lain dengan teman belajarnya. Interaksi ini biasanya terjadi dalam kelompok-kelompok kecil (kelompok belajar). Kelompok-kelompok tersebut biasanya terkumpul dalam kelompok yang diistilahkan dengan KIR (Kelompok Ilmiah Remaja). Dengan demikian maka KIR di sekolah sebenarnya mempunyai peran yang sangat besar untuk meningkatkan kualiatas belajar siswa.

Kelompok Ilmiah Remaja (KIR) adalah kelompok remaja yang melakukan serangkaian kegiatan yang menghasilkan suatu hasil yang disebut karya ilmiah. Karya ilmiah itu sendiri mempunyai arti sebagai suatu karya yang dihasilkan melalui cara berpikir menurut kaidah penalaran yang logis, sistematis, rasional dan ada koherensi antar bagian-bagiannya. KIR merupakan suatu organisasi yang sifatnya terbuka bagi para remaja yang ingin mengembangkan kreativitas, ilmu pengetahuan dan teknologi (Susilowarno, 2003).

Ada beberapa hal yang harus dijadikan bahan pertimbangan dalam membentuk Kelompok Ilmiah Remaja (KIR) di Sekolah, diantaranya adalah waktu kegiatan KIR. Karena Kelompok Ilmiah Remaja (KIR) merupakan kegiatan di luar jam pelajaran sekolah maka, kita harus cerdik dalam menentukan waktu kegiatan, baik untuk kegiatan yang memerlukan waktu yang panjang maupun waktu yang pendek. Setelah itu baru membentuk kelengkapan organisasi seperti kepengurusan, program kerja, pembimbing maupun penerimaan anggota, yang harus disesuaikan dengan kondisi dan kebutuhan di sekolah masing-masing (Susilowarno, 2003).

Tujuan yang harus dicapai oleh anggota KIR secara individual adalah pengembangan sikap ilmiah, kejujuran dalam memecahkan gejala alam yang ditemui dengan kepekaan yang tinggi dengan metode yang 
sistematis, objektif, rasional dan berprosedur sehingga akan didapatkan kompetensi untuk mengembangkan diri dalam kehidupan. Upaya menumbuhkan budaya ilmiah perlu dukungan oleh semua pihak yaitu guru sebagai garda utama untuk membangun motivasi siswa dalam berkarya. Adanya dukungan tersebut akan menumbuhkan kesadaran siswa untuk membuat karya ilmiah yang kreatif dan inovatif.

Budaya penelitian di sekolah harus dikenalkan sejak dini kepada para siswa, tetapi hal tersebut sangat sulit untuk di wujudkan. Budaya ilmiah tidak bisa diharapkan muncul dari kegiatan ekstrakurikuler saja, tapi harus ditanamkan melalui kurikulum semua bidang studi. Artinya harus diintegrasikan dengan metode mengajar guru dan semua kegiatan ekstrakurikuler. Jadi, dalam hal apa pun, kebiasaan untuk berbuat dan berbicara berdasarkan data bisa dibangun. Selain itu, upaya untuk menumbuhkan semangat meneliti di kalangan siswa tidak akan optimal jika sistem pembelajaran kita masih menggunakan pola hafalan.

Ekstrakulikuler KIR di SMP Widiatmika adalah wadah bagi para siswa yang memiliki perhatian besar pada pengembangan sikap ilmiah, kejujuran dalam memecahkan gejala alam yang ditemui dengan kepekaan yang tinggi dengan metode yang sistimatis, obyektif, rasional dan berprosedur. Untuk menghasilkan suatu karya ilmiah yang kreatif dan inofatif, maka salah satu faktor yang menentukan adalah kesiapan siswa itu sendiri dalam mengikuti ekstrakulikuler KIR. Peneliti ingin melihat sejauh mana kesiapan siswa dalam mengikuti kegiatan ekstrakulikuler KIR di SMP Widiatmika.

\section{Metode Penelitian}

Dalam penelitian ini menggunakan pendekatan deskriptif kuatitatif. Pendekatan ini digunakan untuk mengungkap yang menjadi masalah dalam penelitian ini. Sugiyono 2012 menyatakan penelitian kuantitatif digunakan pada realitas/gejala/fenomena yang dapat teramati dan terukur. Penelitian yang dilakukan ini ingin mengungkap fenomena kesiapan siswa untuk mengikuti dan membuat suatu karya ilmiah melalui ekstra KIR di SMP Widiatmika. Pendekatan ini diharapkan dapat mengungkap masalah yang secara rinci dan jelas tentang pentingnya ekstrakulikuler KIR untuk diterapkan dan dilaksanakan secara berkesinambungan agar memperoleh prestasi yang membanggakan.

Tahap Persiapan dimulai dengan menyiapkan buku-buku yang berkaitan dengan teori tentang penelitian, menyiapkan instrument penelitian (berupa angket/kuisioner), menyiapkan garis besar langkah-langkah penelitian, dan menyusun soal kuisioner. Pada tahap pelaksanaan, peneliti melaksanakan kegiatan penelitian di SMP Widiatmika. Adapun hal-hal yang perlu dilakukan dalam tahap ini adalah membagikan lembaran kuisioner ke masing-masing sampel dengan menggunakan metode kuisioner. Pada tahap akhir, peneliti melakukan analisis data melalui hasil dari kuisioner yang sudah diisi. Dengan menggunakan aplikasi Ms. Excel 2007 semua data yang dikumpulkan diolah secara sistematis.

Menurut Sugiyono (2006:72) menyatakan bahwa "Populasi adalah wilayah generalisasi yang terdiri atas objektif dan subjektif yang mempunyai kualitas dan karakteristik tertentu yang ditetapkan oleh peneliti untuk dipelajari dan kemudian di tarik kesimpulan”. Populasi dalam penelitian ini adalah seluruh siswa yang kelas 7, 8 dan 9 di SMP Widiatmika, Kecamatan Kuta Selatan, Kabupaten Badung.

Menurut Suharsimi Arikunto (2006:131) "Sampel adalah sebagian atau wakil populasi yang diteliti". Selain itu menurut Sugiyono (2006:59) menyatakan bahwa "Sampel adalah sebagian dari jumlah dan karakteristik yang dimiliki oleh populasi tersebut, sehingga sampel yang diambil harus representatif (mewakili) dari populasi sampel tersebut berada. Pada penelitian ini sampel yang digunakan adalah siswa yang mengikuti ekstra KIR di SMP SMP Widiatmika, Kecamatan Kuta Selatan, Kabupaten Badung.

Untuk mengumpulkan data pada penelitian ini dilakukan dengan memberikan kuisioner kepada siswa yang berperan sebagai sampel penelitian. Penskoran dengan model skala likert yang telah ditetapkan yaitu: SS (Sangat Setuju) skor 5, S (Setuju) skor 4, C (Cukup) skor 3, TS (Tidak Setuju) skor 2, STS (Sangat Tidak Setuju) skor 1 .

Dalam penelitian ini, peneliti menggunakan analisis deskriptif kualitatif untuk menganalisis dengan membuat kesimpulan dari hasil pengambilan data yang dilakukan di lapangan tentang kesiapan siswa SMP Widiatmika dalam mengikuti ekstrakulikuler KIR.

Data hasil penelitian yang diperoleh akan dianalisis untuk mengetahui seberapa besar kesiapan siswa dalam mengikuti ekstra KIR di SMP Widiatmika kemudian pengolahan data menggunakan persentase yang mengacu pada skala lima (Rofieq 2008) dengan rumus sebagai berikut:

$$
\mathrm{P}=\Sigma \mathrm{F} / \Sigma \mathrm{N} \times 100
$$

Keterangan :

$\mathrm{P}=$ persentase tingkat kesiapan siswa

$\mathrm{F}=$ jumlah skor yang dijawab responden

$\mathrm{N}=$ jumlah skor total 
Hasil persentase akhir tersebut ditafsirkan menggunakan kriteria aspek kualitas dengan skala lima, untuk mengetahui kategori tingkat kesiapan siswa dalam mengikuti ekstra KIR di SMP Widiatmika seperti pada tabel berikut (Rofieq: 2008).

Tabel 1. Kriteria Tingkat Kesiapan Siswa dalam Ekstrakulikuler KIR

\begin{tabular}{llc}
\hline No & \multicolumn{1}{c}{ Persentase $(\%)$} & Kriteria \\
\hline 1 & $80-100$ & Sangat baik \\
2 & $60-79$ & Baik \\
3 & $40-59$ & Cukup \\
4 & $20-39$ & Tidak Baik \\
5 & $0-19$ & Sangat Tidak Baik \\
\hline
\end{tabular}

\section{Hasil dan Pembahasan}

SMP Widiatmika adalah salah satu SMP Swasta yang ada di kabupaten Badung. SMP Widiatmika hadir di tengah masyarakat untuk memberikan bekal pengetahuan, keterampilan, serta pendidikan karakter berbasis tekno humanistik, sehingga pendidikan menjadi lebih bermakna (meaningful learning) bagi peserta didik. Pembelajaran di SMP Widiatmika berbasis e-learning dan konstekstual dengan berbagai model pembelajaran inovatif. Selain itu SMP Widiatmika memberikan layanan dan proses berkualitas yang diramu serta di kemas secara menarik sesuai dengan Empat Pilar Pendidikan sehingga terwujud Pendidikan yang Berwawasan Masa Depan.

Dalam proses pembelajaran, SMP Widiatmika mengacu pada strategi pembelajaran kontekstual dengan berbagai model pembelajaran inovatif yang lebih bersifat student centered. Artinya, pembelajaran yang lebih memberikan peluang kepada siswa untuk mengkonstruksi pengetahuan secara mandiri (self directed) dan dimediasi oleh teman sebaya (peer mediated instruction). Pembelajaran inovatif mendasarkan diri pada paradigma konstruktivistik, yang dapat membantu siswa untuk menginternalisasi, membentuk kembali, atau mentransformasi informasi baru.

Kurikulum yang digunakan oleh SMP Widiatmika adalah Kurikulum Nasional Plus yang disesuaikan dengan kondisi sosial, budaya, ekonomi masyarakat, salah satunya dengan menambahkan mata pelajaran Bahasa Jepang. Adapun SMP Widiatmika menambahkan jumlah jam pelajaran pertemuan perminggunya, dari minimal jumlah jam pelajaran yang telah distandarkan oleh pemerintah pada sejumlah mata pelajaran. Diantaranya adalah IPA sebanyak empat jam pelajaran, Bahasa Inggris sebanyak satu jam pelajaran, Matematika sebanyak satu jam pelajaran, Bahasa Indonesia sebanyak satu jam pelajaran, IPS sebanyak dua jam pelajaran, dan Bahasa Jepang sebanyak dua jam pelajaran. Selain itu kegiatan ektrakulikuler juga berjalan dengan baik di SMP Widiatmika, salah satunya adalah ekstrakulikuler KIR.

Dalam kerangka pendidikan formal, kesiapan siswa dalam mengikuti suatu kegiatan yaitu ekstrakulikuler KIR adalah salah satu faktor penyebab keberhasilan kegiatan tersebut dapat berlangsung dengan baik. Dengan tindakan tentang persiapan, pelaksanaan, maka guru dapat menguatkan motivasi siswa. Kesiapan siswa dalam mengikuti kegiatan KIR merupakan sesuatu yang sangat penting, siswa yang sangat siap mengikuti kegiatan memungkinkan akan memperoleh hasil yang baik pula. Hasil penelitian tingkat kesiapan siswa dalam mengikuti ekstrakulikuler KIR disajikan pada tabel di bawah ini.

Tabel 1. Tingkat Kesiapan Siswa dalam Mengikuti Ekstrakulikuler KIR di SMP Widiatmika

\begin{tabular}{cccc}
\hline Kelas & Skor rata-rata & Persentase $(\boldsymbol{\%})$ & Kriteria \\
\hline VII & 76,51 & 76,51 & Baik \\
VIII & 77,65 & 77,65 & Baik \\
IX & 78,56 & 78,56 & Baik \\
\hline Jumlah & $\mathbf{2 3 2 , 7 2}$ & $\mathbf{2 3 2 , 7 2}$ & \\
Nilai rata-rata & $\mathbf{7 7 , 5 7}$ & $\mathbf{7 7 , 5 7}$ & Baik \\
\hline
\end{tabular}


Dari tabel 1 di atas dapat diamati bahwa tingkat kesiapan siswa dalam mengikuti ekstrakulikuler KIR berada pada kriteria "Baik" dengan rata-rata persentase $77,57 \%$. Sedangkan persentase untuk masing-masing kelas VII, VIII dan IX berturut-turut yaitu 76,51\%, 77,65\% dan 78,56\% dengan kriteria "Baik".

Tabel 2. Distribusi Tingkat Kesiapan Siswa dalam Mengikuti Ekstrakulikuler KIR di SMP Widiatmika

\begin{tabular}{cccc}
\hline Skor & Kriteria & f & Presentase (\%) \\
\hline $80-100$ & Sangat baik & 16 & 40 \\
$60-79$ & Baik & 24 & 60 \\
$40-59$ & Cukup & 0 & 0 \\
$20-39$ & Tidak Baik & 0 & 0 \\
$0-19$ & Sangat Tidak Baik & 0 & 0 \\
\hline
\end{tabular}

Dari tabel 2 menunjukkan bahwa sebagian besar kesiapan siswa dalam mengukuti ekstrakulikuler KIR dikatakan dalam kategori "Sangat Baik" (80-100) dengan frekuensi 16 siswa dan persentase sebesar 40\%, sedangkan sebanyak 24 siswa berada pada kriteria "Baik" (60-79) dengan perentase 60\%. Sehingga secara umum kesiapan siswa dalam mengikuti ekstrakulikuler KIR di SMP sudah dapat dikatakan "Baik".

Menurut Slameto kesiapan adalah keseluruhan kondisi seseorang yang membuatnya siap untuk memberi respon/jawaban di dalam cara tertentu terhadap suatu situasi. Menurut Thorndike sebagaimana yang dikutip oleh Slameto mengartikan kesiapan adalah prasyarat untuk belajar berikutnya. Berbeda dengan Hamalik yang mengartikan kesiapan adalah keadaan kapasitas yang ada pada diri siswa dalam hubungan dengan tujuan pengajaran tertentu. Soemanto mengatakan ada orang yang mengartikan readiness sebagai kesiapan atau kesediaan seseorang untuk berbuat sesuatu. Seorang ahli bernama Cronbach memberikan pengertian tentang readiness sebagai segenap sifat atau kekuatan yang membuat seseorang dapat bereaksi dengan cara tertentu. Sedangkan menurut Djamarah kesiapan untuk belajar merupakan kondisi diri yang telah dipersiapkan untuk melakukan suatu kegiatan. Kesiapan adalah salah satu faktor dalam mengikuti suatu kegiatan yakni berfungsi menimbulkan, mendasari, dan menggerakkan perbuatan. Kebanyakan siswa yang mempunyai kesiapan yang baik akan memperoleh hasil yang maksimal, karena sudah membawa bekal pengetahuan dan tidak kaget terhadap permasalahan di depan yang akan di hadapi. Sebaliknya siswa yang tidak mempunyai kesiapan yang kurang cenderung akan kebingungan dan kurang kreatif dalam menyelesaiakan suatu masalah yang timbul.

Thorndike menggagas beberapa ide penting berkaitan dengan hukum-hukum belajar, di antaranya adalah hukum kesiapam (law of readiness). Dalam hukum kesiapan (law of readiness) ini, semakin siap suatu organisme memperoleh suatu perubahan tingkah laku, maka pelaksanaan tingkah laku akan menimbulkan kepuasan individu sehingga asosiasi cenderung diperkuat. Jadi, semakin siap seseorang menerima atau melakukan sesuatu maka semakin baik pula hasilnya sehingga menimbulkan rasa kepuasan. Hal ini terjadi pada kesiapan siswa dalam mengikuti estrakulikuler KIR berwawasan sains dan teknologi. Siswa yang mempersiapakan materi dengan matang akan mendapatkan ide-ide dalam menyusun judul, proposal ataupun laporan yang kreatif dan inovatif. Dari hasil penelitian ditemukan bahwa kesiapan siswa dalam mengikuti ekstrakulikuler KIR berwawasan sains dan teknologi sangatlah baik. Hal ini berimbas pada ide dan kualitas tulisan siswa. Ide yang dituangkan pada judul karya tulis siswa sangatlah menarik seperti diperlihatkan pada table berikut ini.

Tabel 3. Judul Penelitian pada Ekstrakulikuler KIR di SMP Widiatmika

\begin{tabular}{cc}
\hline Kelas & Judul \\
\hline VII & $\begin{array}{c}\text { Pemanfaatan Lebah Madu (Apis indica) sebagai Indikator } \\
\text { Pendeteksi Gula Alami yang Terkandung pada Produk } \\
\text { Minuman di SMP Widiatmika }\end{array}$ \\
VIII & Pemanfaatan Daun Intaran (Azadirachta indica) \\
& Sebagai Pematang Buah Pisang Ambon (Musa sapientum) \\
IX & Pemanfaatan Jamur Lapuk Putih untuk Merombak Limbah \\
& Zat Warna Industri Tekstil
\end{tabular}

Satu contoh konkrit yang telah dilakukan oleh siswa KIR SMP Widiatmika adalah pemanfaatan jamur untuk mendegradasi limbah tekstil. Ide yang muncul disini adalah bagaimana cara mengolah limbah tekstil 
berwarna agar aman dibuang pada lingkungan sekitar. Banyak cara yang dilakukan yaitu dengan menggunakan bahan kimia, tapi hal tersebut malah menambah masalah yaitu menghasilkan endapan yang banyak dan zat hasil reaksi yang belum tentu aman dibuang pada lingkungan. Sehingga dicarilah cara lain dengan menggunakan jamur sebagai alternatif baru agar limbah tekstil aman jika dibuang pada lingkungan. Ide-ide kreatif seperti ini tidak akan muncul jika siswa tidak memiliki kesiapan dalam mengikuti ekstrakulikuler KIR. Dengan kesiapan materi, maka pemikiran siswa akan terbuka dan banyak mendapatkan ide-ide baru. Kesiapan Siswa dalam ekstrakulikuler KIR berwawasan sains dan teknologi akan merangsang kepeka terhadap segala kejadian atau peristiwa di lingkungan sekitar tempat tinggal, hal ini akan memudahkan mereka untuk berpikir kritis dan inovatif bilamana ada suatu permasalahan yang harus perlu segera dicarikan solusinya.

Dalam dimensi aplikasi pembelajaran, dengan mengikuti ekstrakulikuler KIR berwawasan sains dan teknologi, siswa akan mampu melihat masalah dari berbagai sisi pengetahuan. Siswa akan memiliki kemampuan mengintegrasikan informasi sains, lingkungan, teknologi, dan masyarakat dalam kesatuan yang utuh. Penelitian yang dilakukan sebenarnya ditujukan untuk menyelesaikan masalah yang dijumpai di sekitar kehidupan, sehingga mampu memberikan manfaat nyata pada kehidupan masyarakat sekitar. Pemerintah berharap bahwa lingkungan pendidikan (sekolah) mampu sebagai agent of change bagi kemajuan bangsa. KIR SMP Widiatmika pun $100 \%$ mendukung upaya pemerintah tersebut, dengan cara memecahkan masalah dengan pendekatan metode ilmiah, melakukan riset dengan mengaplikasikan ilmu-ilmu yang didapat dari bangku sekolah diwujudkan dalam suatu produk yang bernilai ekonomi dan dapat dimanfaatkan oleh masyarakat. Siswa sangat aktif dan kreatif dalam mengembangkan ide dan memecahkan masalah yang timbul di dalam kehidupan sehari-hari.

\section{Simpulan}

Dari hasil penelitian dapat disimpulkan bahwa kesiapan siswa dalam mengikuti estrakulikuler KIR berwawasan sains dan teknologi di SMP Widiatmika dikatakan dalam kategori "Sangat Baik" (80-100) dengan frekuensi 16 siswa dan persentase sebesar 40\%, sedangkan sebanyak 24 siswa berada pada kriteria "Baik" (6079) dengan perentase $60 \%$. Sehingga secara umum kesiapan siswa dalam mengikuti estrakulikuler KIR berwawasan sains dan teknologi di SMP Widiatmika sudah dapat dikatakan "Baik".

\section{Daftar Pustaka}

Arikunto, Suharsimi. (2002). Prosedur Penelitian Suatu Pendekatan Praktik. Jakarta: Rineka Cipta.

Cronbach, L. J. (1963). Educational Psychology. New York: Harcourt, Brace \& World, Inc.

Dinatha, N.M. (2017). Kesulitan Belajar Siswa dalam Mata Pelajaran IPA Terpadu. Jurnal Pendidikan Dasar Nusantara. 2 (2): 214-223

Djamarah, S. B. \& Zain, A. (2010). Strategi Belajar Mengajar. Jakarta: Rineka Cipta.

Hamalik, Oemar. (2011). Kurikulum dan Pembelajaran. Jakarta: Bumi Aksara

Laksana, D.N L. (2017). The Effectiveness of Inquiry Based Learning for Natural Science Learning in Elementary School. Journal of Education Technology, 1(1), 1-5.

Soemanto, Wasty. (2006). Psikologi Pendidikan: Landasan Kerja Pemimpin Pendidikan (Cetakan Ke 5). Jakarta: Rineka Cipta.

Sugiyono, (2012). Metode Penelitian Pendidikan Pendekatan Kuantitatif, Kualitatif, dan R \& D. Bandung: Alfabeta.

Susilowarno, R. G. (2003). Kelompok Ilmiah Remaja (Petunjuk Membimbing dan Meneliti Bagi Remaja). Jakarta: Grasindo.

Suyanto, (2009). Kegiatan KIR SebagaiI Usaha Peningkatan Mutu Pendidikan Siswa-siswa Sekolah. Makalah disampaikan dalam workshop pendampingan dosen pada kegiatan KIR di sekolah pada tanggal 28 Juli 2009. Akprind Yogyakarta.

Thorndike, E.L., \& H.P. Hagen. (1977). Measurement and Evaluation in Psychology and Education. New York: John Wiley. 